\title{
Proteasome activity is altered in skeletal muscle tissue of tumour-bearing rats fed a leucine-rich diet
}

\author{
G Ventrucci, M A R Mello and M C C Gomes-Marcondes
}

Nutrition and Cancer Research Laboratory, Department of Physiology and Biophysics, Institute of Biology, State University of Campinas (UNICAMP), Campinas, São Paulo, Brazil, 13083-970

(Requests for offprints should be addressed to M Gomes-Marcondes; Email: cintgoma@unicamp.br)

\begin{abstract}
Leucine can modulate skeletal muscle metabolism by enhancing protein synthesis and decreasing proteolysis. In this study, we investigated the effects of leucine on the ubiquitin-proteasome system in skeletal muscle of pregnant tumour-bearing rats fed a leucine-rich diet. Pregnant Wistar rats were distributed into three groups that were fed a semi-purified control diet (C, control; W, Walker tumour-bearing; $P$, pair-fed) and three other groups of pregnant rats fed a semi-purified leucine-rich diet (L, leucine; WL, Walker tumour-bearing; PL, pair-fed). The tumour-bearing rats were injected subcutaneously with a suspension of Walker 256 tumour cells. Protein synthesis and degradation were measured in gastrocnemius muscle; the total protein content and tissue chymotrypsin-like and alkaline phosphatase enzyme activities were also determined. Muscle protein extracts were run on SDS-PAGE to assess the expression of the myosin heavy chain (MHC), $20 \mathrm{~S} \alpha$ proteasome subunit, 19S MSSI ATPase regulator subunit and 11S $\alpha$ subunit. Although tumour growth decreased the incorporation of $\left[{ }^{3} \mathrm{H}\right]$-Phe, the concomitant feeding of a leucine-rich diet increased the rate of protein synthesis. Muscle proteolysis in both tumour-bearing groups was increased more than in the respective control groups. Conversely, the leucine-rich diet caused less protein breakdown in the WL group than in the W group. Only the W group showed a significant reduction $(71 \%)$ in the myosin content. In WL rats, the $20 \mathrm{~S}$ proteasome content ( $32 \mathrm{kDa}$ band) was reduced, while the expression of the 19S subunit was 3-fold less than in the W group and the 11S proteasome subunit reduced, to around $32 \%$ less than in the $\mathrm{W}$ group. These findings clearly indicate that leucine can stimulate protein synthesis and inhibit protein breakdown in pregnant rats, probably by modulating the activation of the ubiquitin-proteasome system during tumour growth.
\end{abstract}

Endocrine-Related Cancer (2004) 11 887-895

\section{Introduction}

Cachexia occurs in about one-half of all cancer patients (Tisdale 1997) and is the major cause of cancer morbidity and mortality. Cachexia is characterised by a progressive loss of body weight, especially in adipose and muscle tissues, which impairs normal functioning. The loss of skeletal muscle in most cachectic patients and animals involves a decrease in protein synthesis and increased protein degradation, as indicated by a variety of metabolic alterations (Ventrucci et al. 2002, GomesMarcondes et al. 2003).

Muscle proteolysis involves lysosomal and non-lysosomal pathways. Non-lysosomal proteolysis is controlled by the ubiquitin-proteasome system and involves intracellular and myofibrillar protein breakdown (Kee et al. 2002). The muscle ubiquitin pathway is a complex process activated during severe catabolism such as occurs in cancer cachexia (Attaix et al. 1999, Wray et al. 2002). This process involves multiple steps that are proteasome dependent, including protein ubiquitinization mediated by the ubiquitin enzymes E1, E2 and E3 and the 26S proteasome (Attaix et al. 2001), which depends on ATP as an energy source. The 26S proteasome is a proteolytic complex that consists of a central core particle, the $20 \mathrm{~S}$ proteasome subunit, and two regulatory complexes (19S and $11 \mathrm{~S})$ that are bound to the end of the 20S subunit (Glickman \& Ciechanover 2002). 
Leucine plays an important role in skeletal muscle metabolism and can enhance protein synthesis and decrease proteolysis, independently of other branchedchain amino acids (BCAAs) such as isoleucine and valine (Carbo et al. 1996a, Anthony et al. 2001). Leucine regulates protein synthesis in skeletal muscle following food intake (Anthony et al. 2002b). A leucine-rich diet can improve the carcass nitrogen and lean body mass in rats with Walker 256 tumours and in mice with MAC 16 adenocarcinoma (Tisdale 2000, Ventrucci et al. 2001). The importance of insulin and amino acids, mainly BCAAs, in regulating protein synthesis has been studied in several situations (Fulks et al. 1975). The deleterious effects of tumours are more pronounced when associated with pregnancy since maternal nutrition supplies glucose and amino acids for tumour and foetal development (Carbo et al. 1996a) and can result in muscle-wasting proteolysis. In this study, we investigated the effects of leucine on skeletal muscle protein synthesis and degradation, and the activity of the ubiquitin-proteasome system in pregnant tumourbearing rats fed a leucine-rich diet.

\section{Methods}

\section{Animals and diets}

Young female Wistar rats (45 days old, $n=60$ ) were obtained from the animal facilities of the State University of Campinas, São Paulo, Brazil. Female rats were housed overnight with adult males (four females:one male), according to harem methodology (Baker 1991), and the first day of pregnancy was determined based on the detection of sperm in the vaginal smear. All rats were housed in collective cages under standard conditions $\left(22 \pm 2{ }^{\circ} \mathrm{C}, 12\right.$ light: $12 \mathrm{~h}$ darkness cycle, with free access to water and food). Semi-purified diets were used and consisted of a balanced control diet $(\mathrm{C} ; 18 \%$ protein, AIN-93G) and a leucine-rich diet (L; 15\% protein with $3 \%$ leucine). The diets contained the same amount of carbohydrate $(63 \%)$, fat $(7 \%)$ and fibre $(5 \%)$, in accordance with the AIN-93G (Reeves 1993). The corn standard and dextrin were supplied by Corn Products Brazil Ingredients, the vitamin mix was from DSM Nutritional Products (DSM Produtos Nutricionais Brasil Ltda), and the amino acids were from Ajinomoto Interamericana Ind. \& Com. Ltda, Brazil.

The rats were randomly allocated to six groups. Three groups were fed the control diet: C, pregnant; W, pregnant tumour-bearing; $\mathrm{P}$, pregnant pair-fed, this group received the same amount of food as ingested by the $\mathrm{W}$ group. Three other pregnant groups were fed with the leucine-rich diet: L, pregnant; WL, pregnant tumourbearing; PL, pregnant pair-fed, this group received the same amount of food as ingested by the WL group.

\section{Tumour implantation}

The rats in groups $\mathrm{W}$ and $\mathrm{WL}$ received a subcutaneous injection of Walker 256 tumour cells (approximately $0.25 \times 10^{6}$ cells in $0.5 \mathrm{ml}$ saline solution) in the right flank immediately after the confirmation of pregnancy. The other pregnant groups without tumours (controls) received a single injection of $0.5 \mathrm{ml} 0.9 \%(\mathrm{w} / \mathrm{v}) \mathrm{NaCl}$ in the same region as a control manipulation. All of the groups were monitored for 20 days after tumour implantation. The general guidelines UKCCCR (United Kingdom Coordinating Committee on Cancer Research 1988) for animal welfare were followed, and the protocols were approved by the institutional Committee for Ethics in Animal Research (CEEA-IB/UNICAMP, protocol 217-5).

\section{Experimental procedures}

Protein synthesis was assayed in right gastrocnemius muscles, which were weighed and placed in KrebsHenseleit bicarbonate (KHB) buffer $(110 \mathrm{mM} \mathrm{NaCl}$, $25 \mathrm{mM} \mathrm{NaHCO}_{3}, 3.4 \mathrm{mM} \mathrm{KCl}, 1 \mathrm{mM} \mathrm{CaCl}, 1 \mathrm{mM}$ $\mathrm{MgSO}_{4}$ and $1 \mathrm{mM} \mathrm{KH}{ }_{2} \mathrm{PO}_{4}, \mathrm{pH}$ 7.4) supplemented with $5.5 \mathrm{mM}$ glucose and $0.01 \%(\mathrm{w} / \mathrm{v})$ albumin. The muscles were pre-incubated for $30 \mathrm{~min}$ at $37^{\circ} \mathrm{C}$ with continuous gassing $\left(95 \% \mathrm{O}_{2}-5 \% \mathrm{CO}_{2}\right)$ and shaking, as described by Vary et al. (1998). After this period, new KHB buffer supplemented with $5 \mu \mathrm{Ci}$ L- $\left[{ }^{3} \mathrm{H}\right]$ phenylalanine/ml (Amersham) was added and the incubation continued for a further $2 \mathrm{~h}$. At the end of this period, the muscles were homogenised in 10\% trichloroacetic acid (TCA, 1:3 w/v), centrifuged at $10000 \mathrm{~g}$ for $15 \mathrm{~min}$ at $4{ }^{\circ} \mathrm{C}$, and the pellet then suspended in $1 \mathrm{M} \mathrm{NaOH}$ and incubated at $40^{\circ} \mathrm{C}$ for $30 \mathrm{~min}$. Aliquots of this mixture were used to measure the total protein content (Bradford 1976) and to quantify the radioactivity based on liquid scintillation counting of $\beta$ emissions. The rate of protein synthesis was calculated by the amount of radioactive phenylalanine incorporated in a $2 \mathrm{~h}$ period, and was expressed as nanomoles of $\left[{ }^{3} \mathrm{H}\right]-\mathrm{Phe}$ per microgram of muscle protein (Vary et al. 1998).

Protein degradation was assessed using left gastrocnemius muscles which were excised and placed in RPMI 1640 medium and pre-incubated for $30 \mathrm{~min}$ under the same conditions of temperature and gas as described above (Vary et al. 1998). After the initial incubation, the solutions were replaced by KHB buffer supplemented with cycloheximide $(130 \mu \mathrm{g} / \mathrm{ml})$ followed by a $2 \mathrm{~h}$ incubation. At the end of this period, the muscles were dried, weighed and frozen in liquid nitrogen. The muscles and incubation medium were stored at $-80^{\circ} \mathrm{C}$ until analysis. The rate of protein degradation was determined as nanomoles of tyrosine released per microgram of muscle protein per hour, based on fluorometric assay as described by Waalkes \& Udenfriend (1957). 


\section{Enzymatic activities}

The proteins of the gastrocnemius muscle were homogenised in homogenising buffer (HB) $(20 \mathrm{mM}$ Tris, $1 \mathrm{mM}$ dithiothreitol, $2 \mathrm{mM}$ ATP and $5 \mathrm{mM} \mathrm{MgCl}_{2}$ ) and centrifuged at $15000 \mathrm{~g}$ for $15 \mathrm{~min}$ at $4{ }^{\circ} \mathrm{C}$. The resulting supernatant was analysed for total protein content (Bradford 1976) and chymotrypsin-like and alkaline phosphatase activities. Chymotrypsin-like activity was determined using the fluorogenic substrate succinyl-Leu-Leu-Val-Try-7amino-4-methylcoumarin (Suc LLVY-AMC; $0.167 \mu \mathrm{g} / \mu \mathrm{l}$ in $100 \mathrm{mM}$ Tris- $\mathrm{HCl}$, pH 7.4; excitation $360 \mathrm{~nm}$, emission $460 \mathrm{~nm}$ ). The activity was expressed as units of fluorescence per microgram of protein, as a percentage of the control group. Alkaline phosphatase activity was measured using $37 \mathrm{mM}$ p-nitrophenyl phosphate (PNPP) as substrate, and activity was expressed in nanomoles of nitrophenol formed per microgram of muscle protein (Martins et al. 2001).

\section{Myosin and proteasome system}

Skeletal muscle proteins were resolved by SDS-PAGE on $12 \%$ gels followed by Western blotting. The content of myosin heavy chain (MHC) isoforms was assessed using antibody against $\mathrm{MHC}$ at a dilution of 1:250 (Novocastra, Newcastle, UK), followed by detection with a secondary anti-mouse horse radish peroxidase (HRP) antibody (Dako, Carpinteria, USA). The proteasome subunits were analysed by probing $0.45 \mu \mathrm{m}$ enhanced chemical luminescence (ECL) nylon membranes with antibodies against the 20S $\alpha$ proteasome subunit, the 19S MSSI ATPase regulator subunit and the $11 \mathrm{~S} \alpha$ subunit (all from Affinity, Newcastle, UK, and diluted 1:1500) followed by detection with the rat anti-mouse secondary HRP-labelled antibody. Actin was used as the loading control, after probing the mouse actin antibody. Images of the gels were captured (FTI 500Image Master VDS, Pharmacia Biotech) and densitometric analyses of the bands were done with Gel Pro Analyser software (Media Cybernetics, Silver Spring, MD, USA)

\section{Statistical analysis}

The results are expressed as the means \pm S.E.M. Statistical comparisons were done with one-way ANOVA (Gad \& Weil 1994) followed by Bonferroni's test for comparison among groups (Graph Pad Prism software, v3.00 for Windows 98, USA). Statistical significance was considered as a $P$ value below $5 \%$.

\section{Results}

\section{Protein synthesis}

The rate of incorporation of $\left[{ }^{3} \mathrm{H}\right]$-Phe by the gastrocnemius muscle, indicative of protein synthesis, was higher in the
L group (around 23.4\%) than in the corresponding control group, C (Fig. 1A). Tumour growth reduced this parameter in both tumour-bearing groups (W and WL), with a decrease in $\left[{ }^{3} \mathrm{H}\right]$-Phe incorporation by about 47 and $40 \%$ respectively, compared with the respective $\mathrm{C}$ and $\mathrm{L}$ groups. Whereas tumour growth induced severe damage in both pregnant groups (W and WL), the leucine-rich diet fed concomitantly with tumour growth resulted in increased protein synthesis in the WL group (around 1.4-fold higher than in the $\mathrm{W}$ group). These results suggest that leucine probably had a protective effect on skeletal muscle
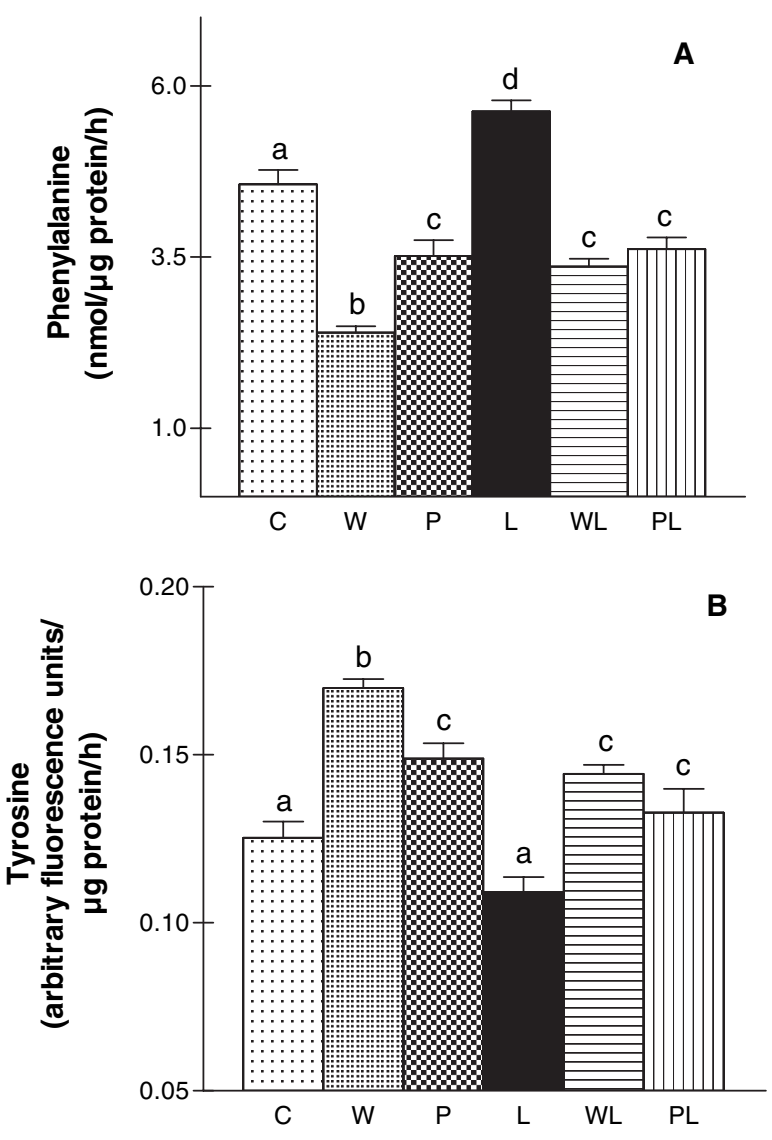

Figure 1 Effects of a leucine-rich diet on protein synthesis (A) and degradation $(B)$ in gastrocnemius muscle from pregnant tumour-bearing rats. Right gastrocnemius muscles from all experimental groups were incubated with $\left[{ }^{3} \mathrm{H}\right]-P h e$ for $2 \mathrm{~h}$ and protein synthesis was then assessed based on the incorporation of radiolabelled amino acid. The contralateral gastrocnemius muscles were similarly incubated for $2 \mathrm{~h}$ with cycloheximide to measure protein breakdown based on the release of tyrosine. At least eight to ten rats were used per group. Abbreviations: C, control; $\mathrm{W}$, tumour-bearing rats; $\mathrm{P}$, pair-fed tumour-bearing rats; $\mathrm{L}$, leucine-rich diet group; $\mathrm{WL}$, tumour-bearing rats receiving leucine-rich diet; PL, pair-fed tumour-bearing group fed with a leucine rich-diet. Columns with different letters above are significantly different $(P<0.05)$. 
metabolism. Anthony et al. (2002b) showed that the oral administration of leucine increased muscle protein synthesis in rats. Pair-fed nutrition does not decrease the rate of protein synthesis, in contrast to the decrease caused by neoplasic growth (Smith \& Tisdale 1993). Indeed as shown here, the incorporation of phenylalanine was not reduced in the $\mathrm{P}$ and PL groups as compared with the tumourbearing groups.

\section{Protein degradation}

Muscle proteolysis, represented by the release of tyrosine from gastrocnemius muscles, was compared between control and leucine-rich diet groups (Fig. 1B). There was no difference in tyrosine release from skeletal muscle in the $\mathrm{C}$ and $\mathrm{L}$ groups. However, during tumour growth, there was an imbalance between the rates of protein synthesis and degradation, especially in the $\mathrm{W}$ groups. Body weight loss and muscle fatigue are common in cancer cachexia and in women with gynaecological cancers (Olt 2003). In recent studies, we observed a body weight loss and a decrease in total body protein in pregnant rats with Walker 256 tumour (Gomes-Marcondes et al. 1998, Ventrucci et al. 2001). As shown in Fig. $1 \mathrm{~B}$, both tumour-bearing groups showed increased tyrosine release, around $33.5 \%$ higher than in the respective control groups, indicating intense muscle protein mobilisation during tumour growth. The tumour-bearing rats fed a leucine-rich diet (WL) showed significantly reduced tyrosine release rates, by around $11 \%$ when compared with the $\mathrm{W}$ group. An increase in tyrosine release was also verified in the pair-fed groups, $\mathrm{P}$ $(18 \%)$ and PL (21\%), when compared with the respective control groups (C and L). However, in the pair-fed situation, the protein breakdown was less intense than in the $\mathrm{W}$ and WL groups.

\section{Enzyme activities}

The chymotrypsin-like activity (Fig. 2A) was increased in all experimental groups compared with group $\mathrm{C}$, although the activity was lower in the WL group (around 17.8\% less) compared with the $\mathrm{W}$ group. In the leucine pair-fed group, muscle chymotrypsin-like activity was also similar to the L group. In addition, as presented in Fig. 2B, there was a significant increase in muscle alkaline phosphatase activity only in the pair-fed groups, P and PL, compared with the $\mathrm{C}$ and $\mathrm{L}$ groups respectively.

\section{MHC in gastrocnemius muscle}

Cancer cachexia wastes whole host tissue by specifically reducing the protein carcass mass. Both of the tumourbearing groups (W and WL) presented a reduction in
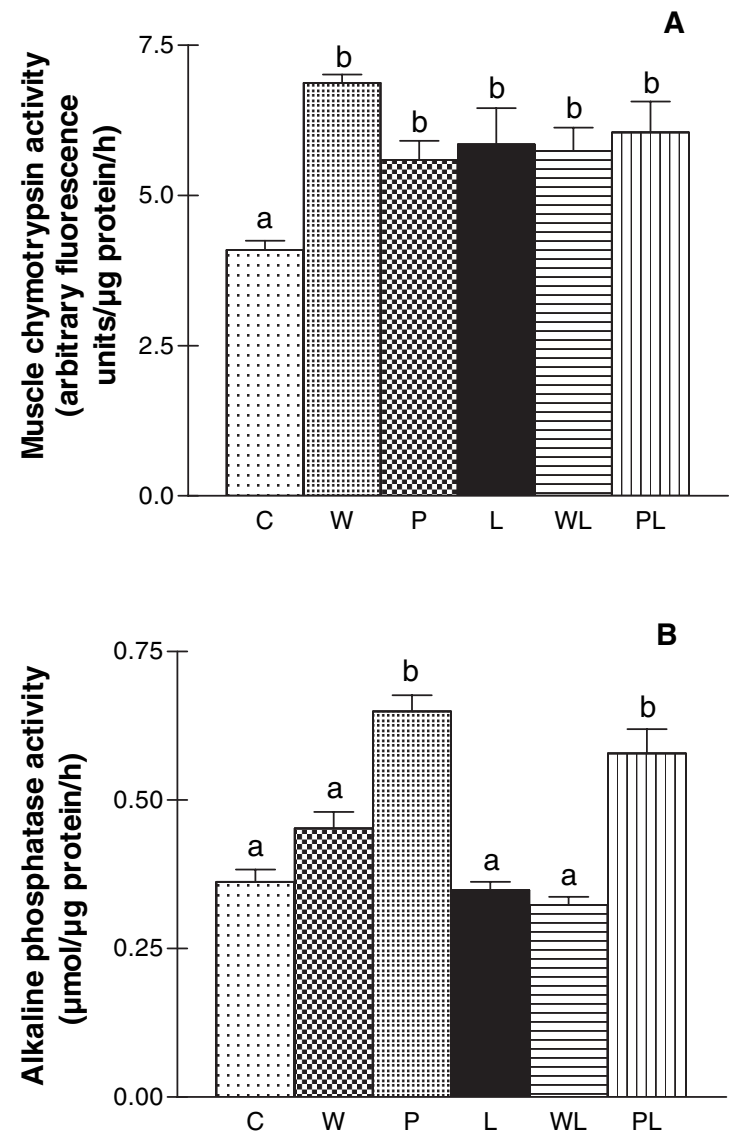

Figure 2 Effects of a leucine-rich diet on muscle enzyme activities in tumour-bearing rats. Muscle chymotrypsin-like and alkaline phosphatase activities were measured in gastrocnemius muscle homogenate. Eight to ten rats per group. For abbreviations, see legend to Fig. 1. The columns are the means \pm S.E.M. for eight to ten rats per group. Columns with different letters above are significantly different $(P<0.05)$.

muscle myosin content (Fig. 3). The reduction in group W was significantly greater $(71 \%)$ than in the corresponding control group (C). On the other hand, there was a significant increase in the myosin content $(47 \%)$ of gastrocnemius muscle in WL rats in comparison to the $\mathrm{W}$ group. Comparatively, as seen in Fig. 3, the muscle myosin content was preserved in both of the pair-fed groups.

\section{Ubiquitin-proteasome system}

Muscle proteolysis in cancer cachexia results from high stimulation of the ubiquitin-proteasome system. Feeding a leucine-rich diet to tumour-bearing rats significantly improved the host muscle mass by altering the expression of the proteasome subunits. Both bands of $20 \mathrm{~S}$ protea- 
$\begin{array}{llllllllllllllllll}C & C & \text { W } & \text { W } & P & P & \text { L } & \text { L } & \text { WL } & \text { WL } & \text { PL }\end{array}$

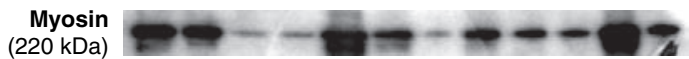

Actin

(42 kDa)
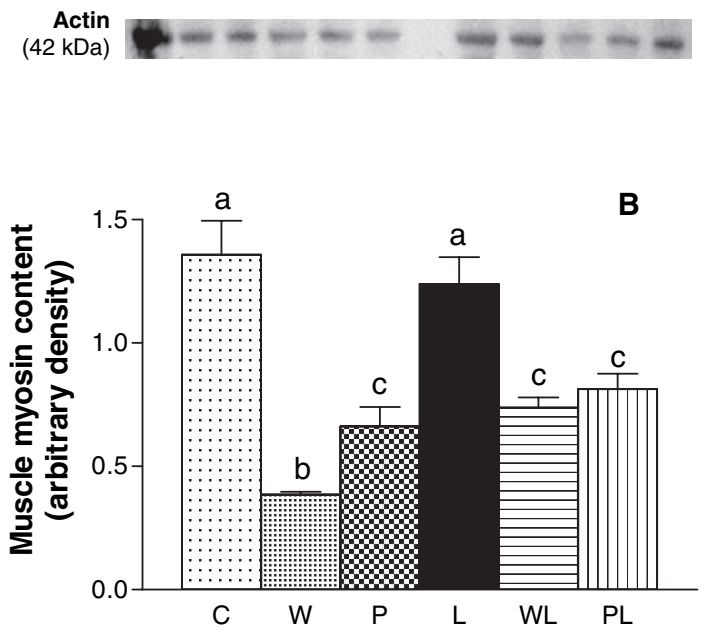

Figure 3 Effects of a leucine-rich diet on muscle MHC content in tumour-bearing rats. (A) Western blot image of $\mathrm{MHC}$ and actin. Actin was used as a loading control. The Western blots are representative data of the best assay from each group (minimum of eight rats per group). (B) Arbitrary densitometric values of myosin expression are analysed for eight individual Western blots. Gastrocnemius muscle homogenates were loaded into SDS-PAGE gels ( $5 \mu \mathrm{g}$ protein/well), later transferred to nylon membranes and blotted with an MHC antibody (diluted 1:250). For details see Methods. For abbreviations see the legend to Fig. 1. The columns are the means \pm S.E.M. for eight to ten rats per group. The expression of actin $(42 \mathrm{kDa}$ band) showed no difference. Different letters above each column indicate statistical difference $(P<0.05)$.

some subunit (Fig. 4) were significantly increased in the W rats when compared with the other groups. Although the expression levels of the two bands of $20 \mathrm{~S}$ proteasome slightly increased in groups fed a leucine-rich diet, in the WL group the 20S subunit expression ( $32 \mathrm{kDa}$ band) was around $32 \%$ less than in the $\mathrm{W}$ group (W, $0.230 \pm 0.012$ arbitary units; WL, $0.156 \pm 0.0154 ; P<0.05)$. There was no significant difference in levels of the $20 \mathrm{~S}$ subunits between the pair-fed groups. The expression of the 19S subunit (Fig. 5) in the WL group was 3-fold lower than in the $\mathrm{W}$ group (W, $0.417 \pm 0.017$; WL, $0.137 \pm 0.010$ arbitary units; $P<0.05$ ), with no difference in the pairfed groups. A slight increase in the $11 \mathrm{~S}$ proteasome subunit (Fig. 6) was observed in the W group compared with group $\mathrm{C}$, but was significantly higher (32\% in the $\mathrm{W}$ group) only when compared with the pair-fed (P and PL) and the leucine-rich diet groups $(\mathrm{W}, 0.511 \pm 0.068$; WL, $0.348 \pm 0.057$ arbitary units; $P<0.05$ ).

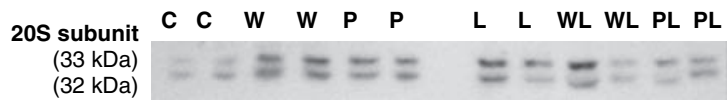

Actin (42 kDa)

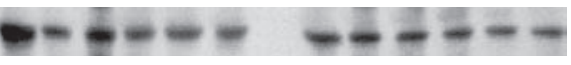

B
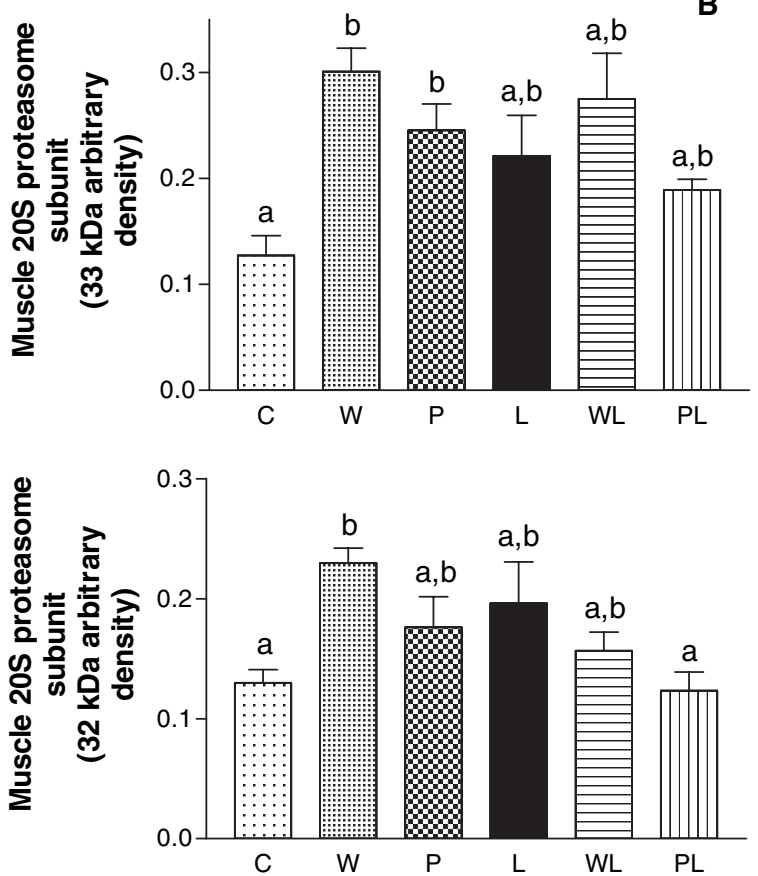

Figure 4 Effects of a leucine-rich diet on expression of the $20 \mathrm{~S}$ $\alpha$ subunit of the $26 \mathrm{~S}$ proteasome in tumour-bearing rats. (A) Western blot image of $20 \mathrm{~S}$ subunit and actin. Actin was used as a loading control. Western blots are representative data of the best assay from each group (minimum of eight rats per group). (B) Arbitrary densitometric values of the expression of the $20 \mathrm{~S}$ subunit (33 and $32 \mathrm{kDa}$ bands) are analysed for eight individual Western blots. Gastrocnemius muscle homogenates were loaded into SDS-PAGE gels ( $5 \mu \mathrm{g}$ protein/well), later transferred to nylon membranes and blotted with a $20 S \alpha$ subunit proteasome antibody (diluted 1:1500). For details see Methods. For abbreviations see legend to Fig. 1. The columns are the means \pm S.E.M. for eight to ten rats per group. The expression of actin ( $42 \mathrm{kDa}$ band) showed no differences. Columns with different letters above are significantly different $(P<0.05)$.

\section{Discussion}

The present findings clearly indicate that a leucine-rich diet altered the activation of the ubiquitin-proteasome system during tumour growth. Amino acids, especially 

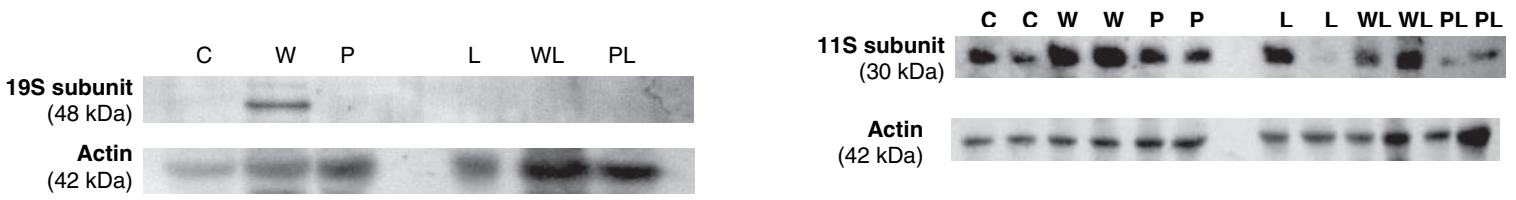

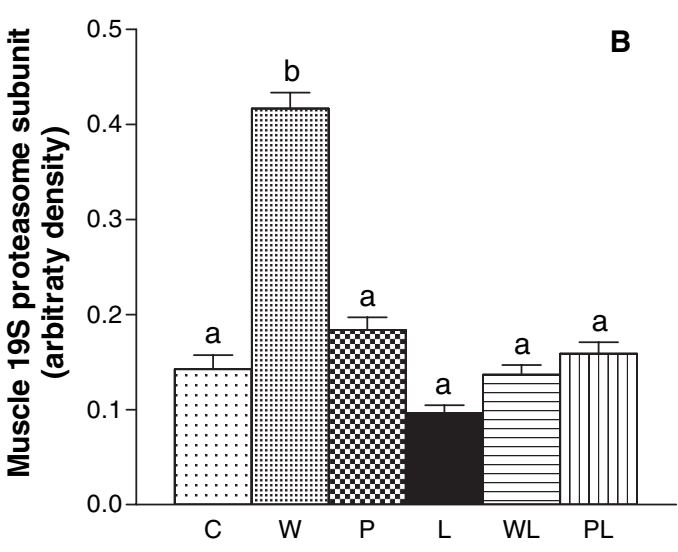

Figure 5 Effects of a leucine-rich diet on expression of the $19 \mathrm{~S}$ MSSI ATPase subunit of the $26 \mathrm{~S}$ proteasome in tumour-bearing groups. (A) Western blot image is representative of the best assay from all experimental groups. (B) Arbitrary densitometric values of eight individual Western blots. Gastrocnemius muscle homogenates were loaded into SDS-PAGE gels $(5 \mu \mathrm{g}$ protein/ well), later transferred to nylon membranes and blotted with a 19S MSSI ATPase subunit proteasome antibody (diluted 1:1500). For details see Methods. For abbreviations see legend to Fig. 1. The columns are the means \pm S.E.M. for eight to ten rats per group. Columns with different letters above are significantly different $(P<0.05)$.

BCAAs, can improve and enhance the rates of protein synthesis in skeletal muscle (Kettelhut et al. 1988, Yoshizawa et al. 1998, Anthony et al. 2002b).

In previous studies, we observed benefits of a leucinerich diet on carcass mass during Walker tumour growth (Ventrucci et al. 2001, Gomes-Marcondes et al. 2003). The present results now show a positive effect of a leucine-rich diet on muscle protein turnover.

Tumour growth causes intense tissue protein turnover by reducing protein synthesis and/or by increasing protein catabolism (Smith \& Tisdale 1993, Tessitore et al. 1993). Since a reduction in caloric intake does not decrease skeletal muscle mass, as shown in pair-fed rats of the present study and verified by other studies in animals with cachectic tumours (Smith \& Tisdale 1993), the cause of the increase in muscle wasting associated with cancer

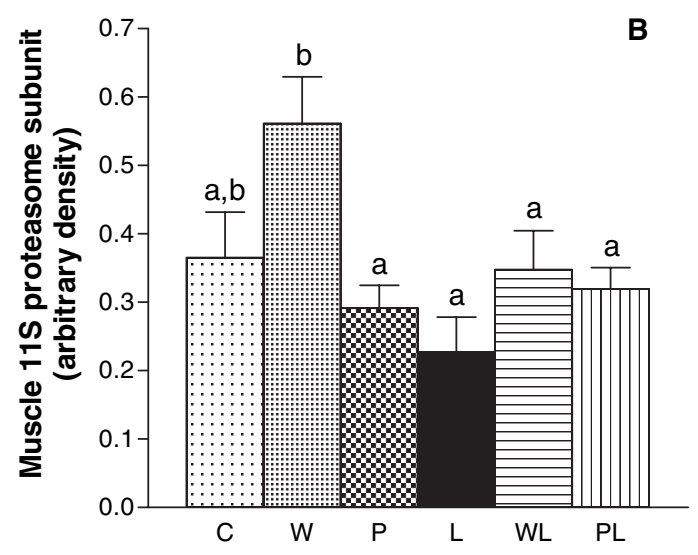

Figure 6 Effects of a leucine-rich diet on expression of the 11S $\alpha$ subunit of the $26 \mathrm{~S}$ proteasome in tumour-bearing groups. (A) Western blot image of the $11 \mathrm{~S} \alpha$ subunit and actin. Actin was used as a loading control. The Western blot is the representative data of the best assay from each group (minimum of eight rats per group). (B) Arbitrary densitometric analysis of $11 \mathrm{~S} \alpha$ expression values for eight individual Western blots. Gastrocnemius muscle homogenates were loaded into SDS-PAGE gels $(5 \mu \mathrm{g}$ protein/well), later transferred to nylon membranes and blotted with an $11 \mathrm{~S} \alpha$ subunit proteasome antibody (diluted 1:500). For details see Methods. For the abbreviations see legend to Fig. 1. The expression of actin ( $42 \mathrm{kDa}$ band) showed no differences. Columns with different letters above are significantly different $(P<0.05)$.

cachexia remains unknown (Tisdale 2002, 2003). Although Walker 256 tumour growth decreases skeletal muscle and whole maternal body weight, feeding a leucine-rich diet prevented the intense reduction, as previously reported (Ventrucci et al. 2001, GomesMarcondes et al. 2003). As shown here, 20 days after tumour implantation, a leucine-rich diet significantly enhanced protein synthesis (Fig. 1A). As reviewed by Anthony et al. (2001), BCAAs can regulate protein synthesis in skeletal muscle. Protein synthesis is stimulated in starved rats, especially after the infusion of amino acids by total parenteral nutrition (Svanberg et al. 1998). These authors also noted that the protein synthesis was enhanced in myofibrillar L6 cell culture, following the addition of amino acids plus insulin-like growth factor (IGF-I) to the culture medium. 
The acute administration of leucine stimulates protein synthesis in various tissues of fasted rat (Vary et al. 1999, Anthony et al. 2002b, Lynch et al. 2002). The administration of leucine by gavage to food-deprived rats elevated the rates of protein synthesis in skeletal muscle (Anthony et al. 2002a). In rats perfused with amino acid solutions, Vary et al. (1999) verified that amino acid supplementation with leucine increased the total protein synthesis in gastrocnemius muscle compared with values obtained with a leucine-poor solution.

Our results support the hypothesis that leucine alone has beneficial effects on skeletal muscle metabolism in tumour-bearing animals, and this was confirmed by the increase in the myosin content (Fig. 3) of the gastrocnemius muscle in WL animals.

In agreement with the idea that leucine alone can improve protein metabolism in tumour-bearing rats, the ingestion of a leucine-rich diet during pregnancy partly inhibited the proteolysis seen in the WL group. Busquets et al. (2000) showed that leucine (10 mM solution) inhibited muscle proteolysis in the extensor digitalis and soleus muscles after incubation with a solution to activate the proteolytic system. Recently, Busquets et al. (2002) reported that the addition of leucine to the incubation medium had no effect on total muscle proteolysis in muscles from Yoshida tumour-bearing rats. In contrast to Busquets et al. (2002), we found that leucine alone stimulated protein synthesis, and inhibited the protein breakdown, probably by reducing the activation of the ubiquitin-proteasome system.

The ATPase subunit of the 19S complex (MSSI) and the $11 \mathrm{~S}$ subunit associate with the $20 \mathrm{~S}$ proteasome (Coux et al. 1996), and these two regulatory complexes can be responsible for modulated activation of proteolysis; in addition, the two 20S subunits, $\alpha$ and $\beta$, can be regulated independently (Attaix et al. 1998, Tanahashi et al. 1999). An increased expression of the MSSI could facilitate the rapid proteolysis of muscles in Walker tumour-bearing rats since the MSSI unit provides energy for the breakdown of ubiquitinylated proteins by the $26 \mathrm{~S}$ proteasome (Coux et al. 1996). The enhanced proteolysis seen in cancer-wasting conditions is ATP dependent (Attaix et al. 1997, 1998) since there is an increase in the expression of several ATPases, including MSSI (Dawson et al. 1995, Fujita et al. 1996, Combaret et al. 1999). Since ATPases provide energy for assembly of the $26 \mathrm{~S}$ proteasome and for the breakdown of ubiquitin conjugates (Attaix et al. 1998, Combaret et al. 1999), the reduction seen here in the 19S proteasome MSSI subunit parallel to an increase in the myosin content suggested that the ubiquitin-proteasome system may be regulated by BCAAs, such as leucine. Larbaud et al. (1996) showed that ubiquitin was also regulated by insulin, with a marked decrease in ubiquitin expression in skeletal muscle after treatment with insulin. Insulin can improve the host carcass protein turnover (Curi et al. 1995, Fernandes et al. 1996a,b), and Anthony et al. (2002a) have observed simultaneous stimulatory effects of insulin and leucine on protein turnover in skeletal muscle.

In an extensive review, Coux et al. (1996) suggested that the $11 \mathrm{~S}$ regulator subunit associates with the $20 \mathrm{~S}$ proteasome to stimulate peptidase activity and could be involved in the final breakdown of peptides derived from protein degradation. Although there was no significant difference in $11 \mathrm{~S}$ expression between the $\mathrm{W}$ and $\mathrm{C}$ groups, this expression was lower in the WL group, suggesting that supplementation with leucine conferred some advantage.

Muscle protein mobilisation can be an adaptable process to several conditions such as pregnancy in order to provide amino acids and an adequate nutritional supply for foetal growth (Carbo et al. 1998); it can also adapt to diseases, to provide amino acids for acute energy metabolism cost and other essential processes for organism survival. On the other hand, tumour growth can affect protein turnover and lead to ineffective amino acid transport between the mother and foetus (Carbo et al. 1996b). Since adequate maternal nutrition is fundamental for foetal welfare and placental development (Godfrey 2002), protein catabolism intensifies in late pregnancy to provide enough nutritional support for foetal growth (King 2000). Conversely, progressive tumour development leads to foetal weight loss (Ventrucci et al. 2001, 2002) and compromises the placentalfoetal exchange (Toledo \& Gomes-Marcondes 1999), mainly through the direct and/or indirect effects of cytokines produced by the tumour and/or host cells (Toledo \& Gomes-Marcondes 2004a,b). Other studies have shown that cytokines (Kettelhut et al. 1988) and, more recently, a proteolysis-inducing factor (GomesMarcondes et al. 2002, Hasselgren et al. 2002, Tisdale 2003) cause intense muscle wasting by activation of the ubiquitin-proteasome system.

The precise mechanism by which leucine and/or BCAAs can induce protein synthesis and/or inhibit protein breakdown needs to be better understood. Investigations are currently underway to address these important questions. In practical terms, our results suggest that the ingestion of a leucine-rich diet could be beneficial in reducing the muscle wasting associated with cancer cachexia.

\section{Acknowledgements}

This study was supported by grants from Fundação de Amparo à Pesquisa do Estado de São Paulo (Fapesp) 
(96/9463-9466, 01/02135-02133, 02/04464-04467), Conselho Nacional de Desenvolvimento Científico e Tecnológico (CNPq) (521048/95-98, 522755/96-98, 350047/0300), Coordenação de Aperfeiçoamento de Pessoal de Nível Superior (CAPES) and Fundo de Apoio ao Ensino e à Pesquisa (FAEP-UNICAMP).

\section{References}

Anthony JC, Anthony TG, Kimball CR \& Jefferson LS 2001 Signalling pathways involved in translational control of protein synthesis in skeletal muscle by leucine. Journal of Nutrition $131856 \mathrm{~S}-860 \mathrm{~S}$.

Anthony JC, Lang CH, Crozier SJ, Anthony TG, MacLean DA, Kimball SR \& Jefferson LS 2002a Contribution of insulin to the translational control of protein synthesis in skeletal muscle by leucine. American Journal of Physiology Endocrinology and Metabolism 282 E1092-E1101.

Anthony JC, Reiter AK, Anthony TG, Crozier SJ, Lang CH, MacLean DA, Kimball SR \& Jefferson LS $2002 b$ Orally administered leucine enhances protein synthesis in skeletal muscle of diabetic rats in the absence of increases in 4E-BP1 or S6K1 phosphorylation. Diabetes 51 928-936.

Attaix D, Taillandier D, Combaret L, Ralliere C, Larbaud D, Aurousseau E \& Tanaka K 1997 Expression of subunits of the $19 S$ complex and of the PA28 activator in rat skeletal muscle. Molecular Biology Reports 24 95-98.

Attaix D, Aurousseau E, Combaret L, Kee A, Larbaud D, Ralliere C, Souweine B, Taillandier D \& Tilignac T 1998 Ubiquitin-proteasome-dependent proteolysis in skeletal muscle. Reproduction, Nutrition and Development 38 153-165.

Attaix D, Combaret L, Tilignac T \& Taillandier D 1999 Adaptation of the ubiquitin-proteasome proteolytic pathway in cancer cachexia. Molecular Biology Reports 26 77-82.

Attaix D, Combaret L, Pouch MN \& Taillandier D 2001 Regulation of proteolysis. Current Opinion in Clinical Nutrition and Metabolic Care 4 45-49.

Baker HL 1991 Reproduction and breeding. In The Laboratory Rat, vol I, ch 7, pp 153-168. Eds HL Baker, JR, Lindseyl \& SH Weisbroth. New York: Academic Press.

Bradford MM 1976 A rapid and sensitive method for quantification of microgram quantities of protein utilizing the principle of protein-dye-binding. Analytical Biochemistry $\mathbf{7 2}$ 248-254.

Busquets S, Alvarez B, Llovera M, Agell N, Lopez-Soriano FJ \& Argiles JM 2000 Branched-chain amino acids inhibit proteolysis in rat skeletal muscle: mechanisms involved. Journal of Cellular Physiology 184 380-384.

Busquets S, Alvarez B, Lopez-Soriano FJ \& Argiles JM 2002 Branched-chain amino acids: a role in skeletal muscle proteolysis in catabolic states? Journal of Cellular Physiology $191283-289$.

Carbo N, Lopez-Soriano FJ \& Argiles JM $1996 a$ Tumour growth and foetal uptake of amino acids in the pregnant rat. European Journal of Cancer 32A 1413-1419.

Carbo N, Lopez-Soriano FJ, Fiers W \& Argiles JM $1996 b$ Tumour growth results in changes in placental amino acid transport in the rat: a tumour necrosis factor alpha-mediated effect. Biochemical Journal 313 77-82.

Carbo N, Costelli P, Lopez-Soriano FJ \& Argiles JM 1998 Tumour growth influences skeletal muscle protein turnover in the pregnant rat. Pediatric Research 43 250-255.

Combaret L, Ralliere C, Taillandier D, Tanaka K \& Attaix D 1999 Manipulation of the ubiquitin-proteasome pathway in cachexia: pentoxifylline suppresses the activation of $20 \mathrm{~S}$ and $26 \mathrm{~S}$ proteasomes in muscles from tumour-bearing rats. Molecular and Biological Reproduction 26 95-101.

Coux O, Tanaka K \& Goldberg AL 1996 Structure and functions of the 20S and 26S proteasomes. Annual Review of Biochemistry 65 801-847.

Curi R, Homem-de-Bettencourt PI, Costa-Rosea LFBP, Ferands LC, El Razi S, Seelaends MC \& Carpinelli AR 1995 Insulin and prostaglandins as signals between tumour and the host immune system. Brazilian Journal of Medical and Biological Research 28 773-779.

Dawson SP, Arnold JE, Mayer NJ, Reynolds SE, Billett MA, Gordon C, Colleaux L, Kloetzel PM, Tanaka K \& Mayer RJ 1995 Developmental changes of the 26S proteasome in abdominal intersegmental muscles of Manduca sexta during programmed cell death. Journal of Biological Chemistry 270 1850-1858.

Fernandes LC, Costa Rosa LFBP, Machado UF \& Curi R $1996 a$ Insulin treatment inhibits glucose and glutamine metabolism in tumour cells from Walker 256 tumour-bearing rats. Cancer Research Therapy and Control 5 35-40.

Fernandes LC, Mattozo CA, Costa Rosa LFBP, Machado UF \& Curi R $1996 b$ Insulin treatment can abolish changes in glucose and glutamine metabolism of lymphocytes and macrophages caused by the implantation of the Walker 256 tumour. Cell Biochemistry and Function 14 187-192.

Fujita J, Tsujinaka T, Yano M, Ebisui C, Saito H, Katsume A, Akamatsu K, Ohsugi Y, Shiozaki H \& Monden M 1996 Antiinterleukin-6 receptor antibody prevents muscle atrophy in colon-26 adenocarcinoma-bearing mice with modulation of lysosomal and ATP-ubiquitin-dependent proteolytic pathways. International Journal of Cancer 68 637-643.

Fulks RM, Li JB \& Goldberg AL 1975 Effects of insulin, glucose, and amino acids on protein turnover in rat diaphragm. Journal of Biological Chemistry 250 290-298.

Gad SC \& Weil CS 1994 Statistics for toxicologists. In Principles and Methods of Toxicology, pp 221-274. Ed. H Wallace. New York: Raven Press Ltd.

Glickman MH \& Ciechanover A 2002 The ubiquitin-proteasome proteolytic pathway: destruction for the sake of construction. Physiological Reviews 82 373-428.

Godfrey KM 2002 The role of the placenta in foetal programming - a review. Placenta 23 (Suppl A) 520-527.

Gomes-Marcondes MCC, Cury L \& Curi R 1998 Consequences of Walker 256 tumour growth for the placental/foetal development in rats. Cancer Research Therapy and Control 5 277-283.

Gomes-Marcondes MC, Smith HJ, Cooper JC, Tisdale MJ 2002 Development of an in vitro model system to investigate the mechanism of muscle catabolism induced by proteolysisinducing factor. British Journal of Cancer 86 1628-1633. 
Gomes-Marcondes MCC, Ventrucci G, Toledo MT, Cury L \& Cooper JC 2003 A leucine-supplemented diet improves protein content of skeletal muscle in young tumour-bearing rats. Brazilian Journal of Medical and Biological Research 36 1589-1594.

Hasselgren PO, Wray C \& Mammen J 2002 Molecular regulation of muscle cachexia: it may be more than the proteasome. Biochemical and Biophysical Research Communications 290 $1-10$.

Kee AJ, Combaret L, Tilignac T, Souweine B, Aurousseau E, Dalle M, Taillandier D \& Attaix Didier 2002 Ubiquitinproteasome-dependent muscle proteolysis responds slowly to insulin release and refeeding in starved rats. Journal of Physiology 546 765-776.

Kettelhut IC, Wing SS \& Goldberg AL 1988 Endocrine regulation of protein breakdown in skeletal muscle. Diabetes Metabolism Reviews 4 751-772.

King JC 2000 Physiology of pregnancy and nutrient metabolism. American Journal of Clinical Nutrition 71 (Suppl 5) 1218S-1225S.

Larbaud D, Debras E, Taillandier D, Samuels SE, Temparis S, Champredon C, Grizard J \& Attaix D 1996 Euglycemic hyperinsulinemia and hyperaminoacidemia decrease skeletal muscle ubiquitin mRNA in goats. American Journal of Physiology 271 E505-E512.

Lynch CJ, Hutson SM, Patson BJ, Vaval A \& Vary TC 2002 Tissue-specific effects of chronic dietary leucine and norleucine supplementation on protein synthesis in rats. American Journal of Physiology Endocrinology and Metabolism 283 E824-E835.

Martins MJ, Negrao MR \& Hipolito-Reis C 2001 Alkaline phosphatase from rat liver and kidney is differentially modulated. Clinical Biochemistry 34 463-468.

Olt GJ 2003 Fatigue and gynaecologic cancer. Current Women's Health Reports 3 14-18.

Reeves PG, Nielsen FH \& Fahey J 1993 AIN-93 purified diets for laboratory rodents: final report of the American Institute of Nutrition ad hoc writing committee on the reformulation of the AIN-76 rodent diet. Journal of Nutrition 123 1939-1951.

Smith KL \& Tisdale MJ 1993 Increased protein degradation and decreased protein synthesis in skeletal muscle during cancer cachexia. British Journal of Cancer 67 680-685.

Svanberg E, Jefferson LS, Lundholm J \& Kimball SR 1998 Postprandial stimulation of muscle protein synthesis is independent of changes in insulin. American Journal of Physiology 272 E841-E847.

Tanahashi N, Kawahara H, Murakami Y \& Tanaka K 1999 The proteasome-dependent proteolytic system. Molecular Biology Reports 26 3-9.
Tessitore L, Costelli P, Bonetti G \& Baccino FM 1993 Cancer cachexia, malnutrition, and tissue protein turnover in experimental animals. Archives of Biochemistry and Biophysics 306 52-58.

Tisdale MJ 1997 Biology of cachexia. Journal of the National Cancer Institute 89 1763-1773.

Tisdale MJ 2000 Metabolic abnormalities in cachexia and anorexia. Nutrition 16 1013-1014.

Tisdale MJ 2002 Cachexia in cancer patients. Nature Reviews in Cancer 2 862-871.

Tisdale MJ 2003 The 'cancer cachectic factor'. Supportive Care in Cancer 11 73-78.

Toledo MT \& Gomes-Marcondes MC 1999 Morphologic aspect of the placenta in young and adult pregnant rats bearing Walker 256 carcinoma. Oncology Research 8 359-366.

Toledo MT \& Gomes-Marcondes MCC 2004a Cancer in pregnancy enhances the expression of PARP and caspase 3 and cytochrome c release in placenta. Biology of Reproduction (In press).

Toledo MT \& Gomes-Marcondes MCC 2004b Placental glycogen metabolism changes during Walker tumour growth. Placenta 25 456-462.

Vary TC, Dardevet D, Grizard J, Voisin L, Buffiere C, Denis P, Breuille D \& Obled C 1998 Differential regulation of skeletal muscle protein synthesis turnover by insulin and IGF-I after bacteremia. American Journal of Physiology Endocrinology and Metabolism 275 E584-E593.

Vary TC, Jefferson LS \& Kimball SR 1999 Amino acid-induced stimulation of translation initiation in rat skeletal muscle. American Journal of Physiology 277 E1077-E1086.

Ventrucci G, Mello MAR \& Gomes-Marcondes MCC 2001 Effects of a leucine-supplemented diet on body composition changes in pregnant rats bearing Walker 256 tumour. Brazilian Journal of Medical and Biological Research 34 333-338.

Ventrucci G, Mello MAR \& Gomes-Marcondes MCC 2002 Effects of a leucine supplemented diet on intestinal absorption in tumour-bearing pregnant rats. Biological Medical Central Cancer 27 (http://www.biomedcentral.com/1471-2407/2/7).

Waalkes TP \& Udenfriend S 1957 A fluorometric method for the estimation of tyrosine in plasma and tissues. Journal of Laboratory Clinical Medicine 50 733-736.

Wray CJ, Mammen JM \& Hasselgren PO 2002 Catabolic response to stress and potential benefits of nutrition support. Nutrition 18 971-977.

Yoshizawa F, Kimball SR, Vary TC \& Jefferson LS 1998 Effect of dietary protein on translation initiation in rat skeletal muscle and liver. American Journal of Physiology 275 E814-E820. 